\title{
Coulisses
}

Revue de théâtre

14 | Printemps 1996

Varia

\section{Humeurs au sortir du spectacle}

Propos recueillis par Françoise et Pierre Chambefort

\section{Françoise Chambefort et Pierre Chambefort}

\section{(2) OpenEdition}

\section{Journals}

Édition électronique

URL : http://journals.openedition.org/coulisses/4869

DOI : $10.4000 /$ coulisses.4869

ISSN : 2546-9460

Éditeur

Presses universitaires de Franche-Comté

\section{Édition imprimée}

Date de publication : 1 mai 1996

Pagination : 79-80

ISSN : $1150-594 \mathrm{X}$

\section{Référence électronique}

Françoise Chambefort et Pierre Chambefort, « Humeurs au sortir du spectacle », Coulisses [En ligne], 14 | Printemps 1996, mis en ligne le 20 mars 2019, consulté le 24 septembre 2020. URL : http:// journals.openedition.org/coulisses/4869; DOI : https://doi.org/10.4000/coulisses.4869

Ce document a été généré automatiquement le 24 septembre 2020

Coulisses 


\title{
Humeurs au sortir du spectacle
}

Propos recueillis par Françoise et Pierre Chambefort

\author{
Françoise Chambefort et Pierre Chambefort
}

\section{Il y a un style Brozzoni}

1 «Je ne m'attendais pas à ça, je m'attendais à un truc morbide à cause du thème de la pièce et en fait c'était très enlevé, très joyeux. "

2 "C'est une pièce courageuse : trois heures et demie de spectacle sur le thème du chômage, même si cela m'intéresse et que je me sens concernée, ce n'était pas évident. »

3 «Le spectacle est très homogène. Alors que la première partie s'essouffle parfois (notamment à cause du jeu de Shakespeare) les scènes violentes de la deuxième partie resserrent le côté dramatique de la pièce. Beaucoup d'idées sur le travail coryphée / chœur, sur l'énergie. »

4 «Ce qui m'a beaucoup plu, c'est que les didascalies fassent partie du jeu.»

5 «À la fin, Hans tombe dans le haut-fourneau comme un martyr mais ce n'est pas montré ; le spectateur le voit seulement dire au revoir à tous ses collègues ouvriers, debout, en noir, et cette scène est magnifique. Là, l'instant est fort, simple. Comme quoi il aurait été possible d'évoquer la mort, le sexe, la violence avec force sans les montrer.»

6 "L'atmosphère des hauts fourneaux est très bien rendue, notamment par l'éclairage. Le spectateur ressent en permanence la présence toute proche du brasier.

Les changements de scène, entrecoupés par des passages chantés très beaux, sont vraiment bien faits. "

7 «Le thème de la pièce (le monde ouvrier) et l'implication de la population de Montbéliard qui s'est faite au travers des différents ateliers ont fait du spectacle un spectacle total. »

8 «Il y a un style Brozzoni. » 


\section{Le rythme}

9 "J'ai beaucoup aimé la première partie parce qu'elle était très diversifiée, mais il y avait des longueurs dans la deuxième, notamment le monologue de Shakespeare à la fin, je ne l'ai pas trouvé très accessible. »

10 «Je trouve que c'est dommage de remettre un chant après le monologue de Shakespeare à la fin parce que ça le réduit. »

11 "Le rythme est donné par l'apport musical. Mais il y a des longueurs parce que l'émotion est toujours sur la violence. Il manque une certaine simplicité que je trouve seulement dans le jeu de Hans. Tout est traité en force et pas en subtilité, ce qui donne une uniformité. C'est vrai que le thème c'est la revendication, la douleur, la marginalité, le chômage ; mais il manque des silences, des instants de respiration et d'émotion, ce qui fait que j'ai ressenti des longueurs même si je ne me suis ennuyée à aucun moment. »

12 « Dans l'hyperréalisme (et ici ce n'en est pas), dans la crudité, l'architecture industrielle (les lumières de raffineries par exemple), il y a souvent une certaine poésie. Dans ce spectacle, on ne retrouve pas cette poésie là. »

\section{Quelques personnages}

Hans

13 «La scène où il est dans le lit d'enfant m'a beaucoup touchée : il regarde la télé, il ne parle pas mais beaucoup de choses passent à travers son regard. Il est le seul qui joue avec des nuances. »

Schmelzer, le chef d'équipe de l'aciérie

14 «Ce personnage a une dignité et une hargne extraordinaire dans sa révolte.»

Anna

15 «Elle a un très beau personnage qui pourrait être vraiment émouvant, mais elle le joue de façon très monocorde. Pourtant elle aurait dû être un des personnages principaux puisqu'avec Hans, son mari, ils représentent un peu la condition de tous les autres ouvriers. »

\section{Le sexe}

16 "Certaines personnes ont été choquées par les scènes chaudes alors qu'elles sont moins choquées par le discours de la chef du personnel à la fin qui est quelque chose qui existe vraiment ; c'est un discours dur mais qui existe dans les entreprises. On est aussi moins choqué quand Hans se jette dans le feu et meurt que par les scènes de sexe qui nous renvoient à des choses qui sont plus difficiles pour nous à gérer. »

17 «Ces scènes sont très courageuses, aussi bien de la part du metteur en scène que des comédiens. Elles sont très crues et à la limite de la pornographie, mais j'ai eu le sentiment que c'était trop ou pas assez (et Dieu sait que ça va loin) : soit il fallait aller jusqu'au bout de la pornographie, soit traiter ces scènes de façon très poétique pour les transfigurer totalement. » 
18 «Le texte est parasité par l'action pendant les scènes pornos et il perd de sa force. Pourtant le contraste entre ces scènes très crues et ce texte presque poétique est très beau.»

19 «Les scènes de nu ne m'ont pas gêné sauf la fellation parce que je trouve que c'était faux et que ça faisait toc par rapport au reste, les autres scènes sont plus crédibles. » "Les scènes de sexe m'ont choqué, mais elles font vraiment partie de la pièce de Turrini (Charlie Brozzoni n'a rien coupé ni rajouté) et elles servent efficacement le spectacle. » «Les scènes de nu m'ont rassuré : par rapport aux sexes d'hommes que j'ai vu et par rapport à leur taille, je me suis trouvé rassuré et je me suis trouvé plus normal. »

22 "Une scène que je trouve vraiment très dure, c'est la scène de violence avec le Yougoslave : c'est très difficile à supporter. Ça m'a fait penser au nazisme. Par contre les scènes de porno ne m'ont pas dérangé, bien qu'on eût pu passer plus rapidement sur le film; ce qui était intéressant, c'était qu'Anna prenne cette décision de tourner cette scène, et tout ce que ça engendre dans les relations de son couple. » «La scène de violence m'a choqué parce que j'avais peur pour l'acteur lui-même; les ouvriers lui attachent les mains et lui mettent le sexe dans un tube d'acier dont ils chauffent l'autre bout avec un chalumeau. Cela joue sur une ambiguïté qui est malsaine : le spectateur a peur que cela dure trop longtemps et que l'acteur se fasse réellement brûler.»

24 «Est-ce un spectacle qui pourra bien se vendre? Les scènes "hard" risquent de choquer beaucoup de spectateurs. Pourtant cela peut être un pari, une initiation. »

«Ce que j'ai préféré c'est la manière dont est traitée l'histoire de Hans et de Anna, très banale, très ordinaire, qui contraste avec l'outrance du reste du spectacle. De ce quotidien, les comédiens ont fait sentir le non-dit: Anna et son envie d'être mère, de préparer une naissance; Anna qui s'échappe de l'usure du quotidien par le rêve de la publicité en quadrichromie, sur papier glacé. Anna et Hans, un amour présent sans lyrisme tapageur, avec le désir du moment, l'étreinte. Si bien que, lorsque Anna vend son corps pour une vidéo porno, si la scène est réaliste dans sa représentation, elle n'est pas obscène.; chacun des partenaires poursuit son propre rêve. Mais dans cette machinerie sexuelle, tout d'un coup intervient le plaisir, c'est ce que verra Hans, lorsqu'il regardera la cassette.: le plaisir de celle qu'il désire, qu'il aime et veut combler, c'est ce qui le jettera hors de lui. Les trois comédiens Thomas Desfossés, l'ouvrier, Fabienne Monteiro-Braz, Anna, Laurent Halgand, Hans, sont remarquables de justesse, de retenue, de tendresse. Leur sincérité, leur pudeur, apportent un démenti radical à la pornographie, caricature de la sexualité et de l'amour. J'ai admiré leur courage à montrer sur scène, devant le "grand public ", leur nudité. Leur présence, leur sensibilité redonnent à des mouvements intimes, si galvaudés ailleurs, leur plénitude et leur humanité.» 
Éléments moins performants in Chronique

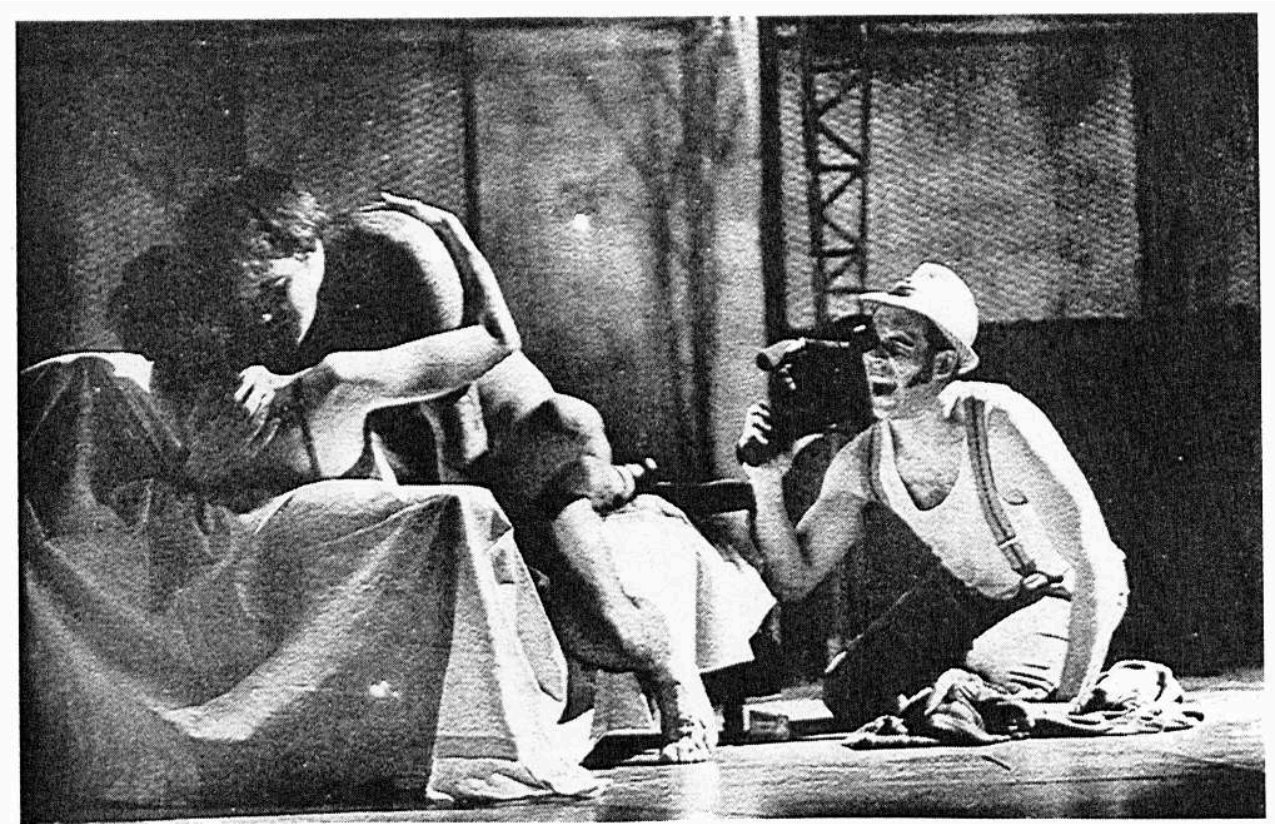

Photo Rémi Caritey 